\title{
Agnihotra as an inexpensive method to treat HIV/AIDS - A pilot study
}

\author{
S. A. Ramadass ${ }^{1}$, Lancy D'souza ${ }^{2}$, Karthik Pandit ${ }^{3}$, Madhu Karnat S. ${ }^{4}$, Ulrich Berk ${ }^{5 *}$ \\ Ananta Bharatha Charitable Trust ${ }^{\circledR}$, Mysore, India ${ }^{1,4}$ \\ Maharaja's College, University of Mysore, Mysore, India ${ }^{2}$ \\ S N Pandit Health Care Services LLP Mysore, Mysore, India ${ }^{3}$ \\ German Association of Homa Therapy, Mühlingen, Germany ${ }^{5}$
}

\section{KEY WORDS}

HIV/AIDS

Agnihotra

Human Health

*Corresponding Author:

Ulrich Berk, PhD

President, German Association of Homa

Therapy, Mühlingen, Germany

Contact no: +91-9981114904

E-mail:dght@homatherapie.de

\begin{abstract}
Background: Despite four decades of searching, no vaccine exists yet for HIV/AIDS, and it is still a big problem in many countries of the world.

Purpose: Finding a simple method which is affordable, and which could help avoid side effects which the commonly used antiretroviral drugs often show, is the need of the moment.

Method: A group of HIV positive children have been performing daily sunrise/sunset Agnihotra themselves under supervision for two years. Data were collected on viral load and CD4 counts before and after that. Repeated measure ANOVA was employed to find out the effectiveness of Agnihotra on reduction of viral load and increase in CD4 count.

Results: Data shows general health improved measurably as viral load went down and CD4 values increased.

Conclusion: These preliminary results show good potential of Agnihotra for HIV/AIDS patients and a randomized controlled trail is suggested.
\end{abstract}

doi: 10.38205/imcr.020106

\section{Introduction}

Control and prevention of the HIV/AIDS epidemic remains at the centrepiece of worldwide health issues. The most common mainstream treatments to control HIV/AIDS symptoms are a combination of usually three out of several antiretroviral drugs. Depending on which drugs are used, various side effects (both short-term and long-term) have been noted including hypersensitivity or allergic reactions, nausea, bleeding, heart disease, high blood sugar, insomnia and irritability. and more (1).

Despite some relative successes, developing countries especially continue to suffer disproportionately because of costs and resources and lifestyle issues. Therefore, alternative treatments are needed.

This pilot study enumerates a simple, inexpensive, holistic process which may make great strides in helping create more far-reaching inroads into care, treatment and prevention of HIV/AIDS.

The non-profit organization Ananta Bharatha Charitable Trust ${ }^{\circledR}$ in Mysore (South India) is helping HIV positive children, most of them orphans or semi-orphans. Agnihotra - a Vedic fire method to heal the atmosphere and our environment and which has very beneficial effects on Human Health also was introduced.

Agnihotra is a healing fire technique which is prepared from dried cow dung and cow's ghee (both medicinal substances) in a copper pyramid of fixed size and shape and performed exactly at sunrise and sunset.

It is a gift to humanity from ancient Vedic sciences of bioenergy, medicine, agriculture and climate engineering (2). A concise introduction to the method of Agnihotra you find here: (3). Many experiments done by modern science have confirmed that Agnihotra purifies our environment - our atmosphere, soil, and water resources (4). A more detailed description of how to perform Agnihotra is given in (2) and in (5). Homa Therapy is based on regular performance of Agnihotra, and in addition to that some more disciplines are introduced especially in the field of Homa Farming.

There are many reports showing the beneficial effect of Agnihotra on Human Health (ranging from asthma to tumours, and including positive effects on our minds, like stress reduction etc.) (6). For detail about the effects on yield, disease prevention and control of pests see (5). In this pilot study the effect of Agnihotra on HIV positive children was observed.

\section{Methodology}

In the study 10 children of both sexes with HIV infection were observed over a period of two years. They all stayed in one place (in the Amma Mane centre of Ananta Bharatha Charitable Trust ${ }^{\circledR}$, a residential home for HIV postitive children), got healthy vegetarian food, and were treated with respect.

They were provided with normal south Indian food with organic items, ghee was used more, regularly different kinds of fruits and vegetables were provided (milk, millets, dry fruits were also provided). Ragi (Jowar) Rotis were given instead of wheat; instead of white rice unpolished rice was used. Also, different millets were used to prepare different kinds of dishes. In addition to that they were performing Agnihotra twice every day and consumed Agnihotra Ash regularly.

In this pilot study, objective parameters were considered for the analysis. The children were under regular watch by a 
team of experts comprised of medical practitioners, psychologists and social workers. Data were collected in June 2015 (before Agnihotra was started) and then again in June 2017. During that period, all children performed Agnihotra regularly. Parameters tested were Viral Load, and CD4. Informed consent was obtained from all patients and their parents for the study. Informed consent were taken as per guidelines.

\section{Data analysis and interpretation}

Statistical methods like descriptive statistics and repeated measure ANOVA as inferential statistics were employed for data analysis. A repeated measures ANOVA is also referred to as a within-subjects ANOVA or ANOVA for correlated samples. In the present study, viral load and CD4 counts were taken repeatedly twice over the period of two years for the same sample of male and female subjects. To see the overall increase/decrease in these selected variables and differential decrease/increase gender-wise, repeated measure ANOVA was employed.

\section{Results}

A significant decrease in the mean Viral Load values from the year 2015 to 2017 was observed $(F=9.737 ; p=.014$, Table 2$)$, where we find a decrease of 39759.10 units in the mean
Table 1: Total included participants for the study and their mean ages

\begin{tabular}{|c|l|c|c|}
\hline S. No. & Gender & Count & Mean \\
\hline 1. & Male & 7 & 13 \\
\hline 2. & Female & 3 & 11.6 \\
\hline 3. & Total & 10 & 1.6 \\
\hline
\end{tabular}

Viral Load. (Figure 1) (pre mean 55990.20; post mean 16231) overall, irrespective of the gender. Comparatively gender wise there was more decrease in the viral load for female subjects as compared to male subjects, however, this decrease was not statistically significant between the genders, as the observed $\mathrm{F}$ value of 1.583 failed to reach the significance level criterion of .05 level $(\mathrm{p}=.244)$.

In the case of CD4 count also, a significant increase in the mean values from the year 2015 to 2017 was observed ( $F=6.522 ; p=.034$, Table 3 ), where we find an increase of 107.20 units in the mean CD4 count (pre mean 596.50; post mean 703.70, Figure 2). However, gender wise no differential decrease was observed among male and female patients as the observed $\mathrm{F}$ value of 3.711 failed to reach the significance level criterion of .05 level $(p=.090)$.

Table 2: Mean Viral Load values of male and female patients in 2015 and 2017 and results of repeated measure ANOVA

\begin{tabular}{|c|c|c|c|c|c|}
\hline \multirow[t]{2}{*}{ Gender } & \multicolumn{2}{|c|}{2015 (pre-viral load) } & \multicolumn{2}{|c|}{2017 (post-viral load) } & \multirow[t]{2}{*}{ Change } \\
\hline & Mean & S.D & Mean & S.D & \\
\hline Male (7) & 38721.86 & 46822.41 & 10432.29 & 19484.23 & -28289.57 \\
\hline Female (3) & 96283.00 & 78573.73 & 29761.67 & 43429.84 & -66521.33 \\
\hline Total (10) & 55990.20 & 60055.15 & 16231.10 & 27557.47 & -39759.10 \\
\hline Test statistics & & & $\begin{array}{l}\text { e-post) }=9 \\
\text { ender) }=1\end{array}$ & & \\
\hline
\end{tabular}

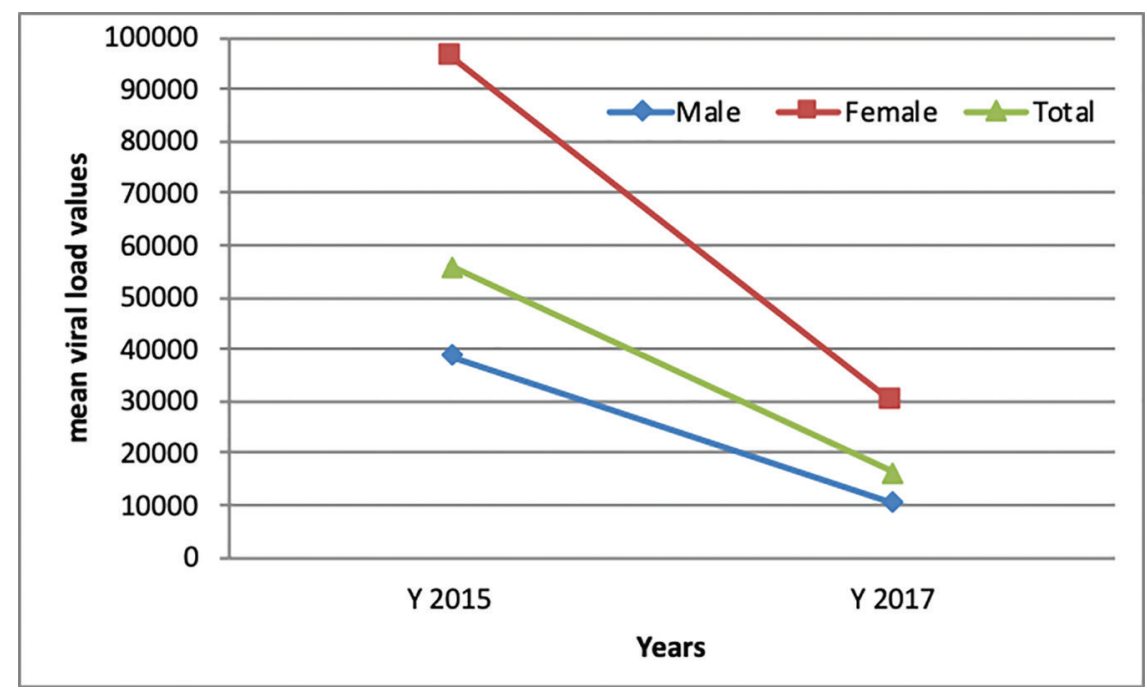

Fig. 1: Mean Viral Load values of male and female patients in 2015 and 2017. 
Table 3: Mean CD4 values of male and female patients in 2015 and 2017 and results of repeated measure ANOVA

\begin{tabular}{|c|c|c|c|c|c|}
\hline \multirow[t]{2}{*}{ Gender } & \multicolumn{2}{|c|}{2015 (pre CD4 count) } & \multicolumn{2}{|c|}{2017 (post CD4 count) } & \multirow[t]{2}{*}{ Change } \\
\hline & Mean & S.D & Mean & S.D & \\
\hline Male (7) & 649.86 & 238.97 & 687.57 & 215.22 & 37.71 \\
\hline Female (3) & 472.00 & 207.88 & 741.33 & 177.00 & 269.33 \\
\hline Total (10) & 596.50 & 234.64 & 703.70 & 196.25 & 107.20 \\
\hline Test statistics & & & $\begin{array}{l}\text { post) }= \\
\text { (der) }=\end{array}$ & & \\
\hline
\end{tabular}

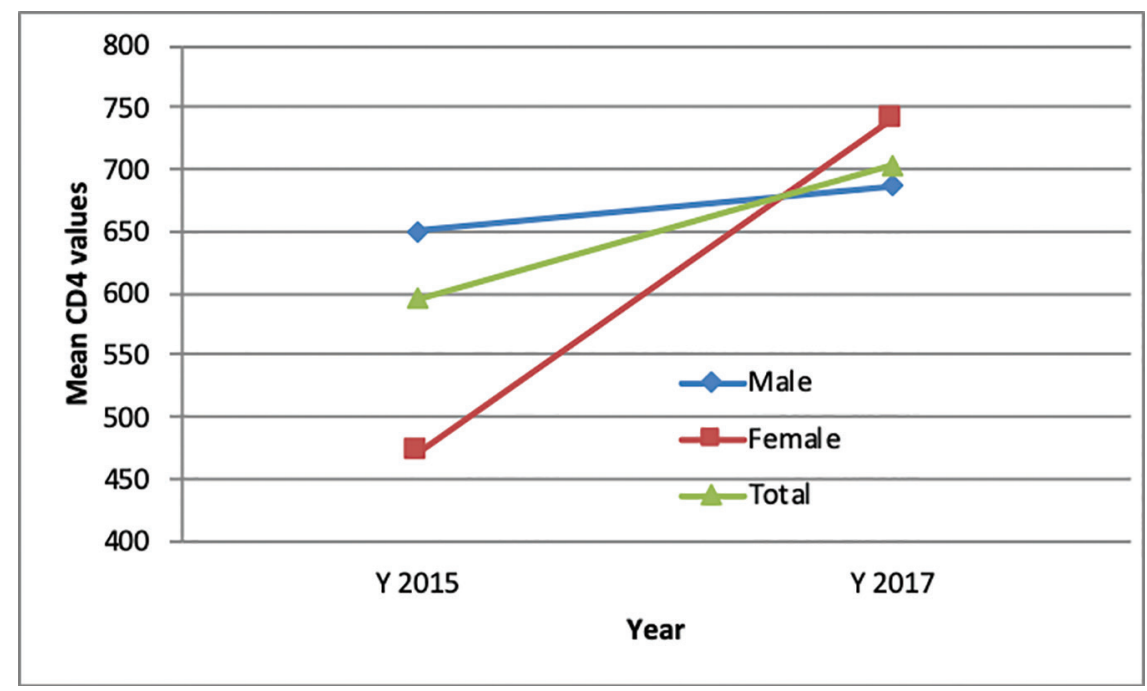

Fig. 2: Mean CD4 values of male and female patients in 2015 and 2017.

\section{Discussion}

The most common mainstream treatments to control HIV/ AIDS symptoms are a combination of usually three out of several antiretroviral drugs. Depending on which drugs are used, various side effects (both short-term and long-term) have been noted including hypersensitivity or allergic reactions, nausea, bleeding, heart disease, high blood sugar, insomnia, and irritability. and more (1).

Over four decades of extensive daily performance of sunrise/sunset Agnihotra have yielded many reports of healing in many different diseases, but during all these years no negative side effects have been reported (7).

The treatment protocol with Agnihotra resulted in significant reduction of Viral Load and increase in CD4 count. Also, there was a reduced frequency of opportunistic infections as reported by physicians.

The mechanisms of how Agnihotra reduces Viral Load and strengthens the immune system have not yet been studied. One possible mechanism is that Agnihotra reduces either reproduction of viruses or their virulence.

If we examine the bacterial body, previous studies (8) show that bacteria are reduced in Agnihotra environment and also the virulence of harmful bacteria like Klebsiella pneumonia and Staphylococcus aureus are reduced as there is a

- Loss of capsule formation

- Loss of haemolytic activity

- Decreased resistance to phagocytosis

The effects of the ancient practices have provided positive health effects in various diseases but often ignored as unscientific and disregarded especially by the modern medicine and scientific community, but it is an area to explore and many such practices are being converted into evidence slowly and taking its place in the scientific world $(9,10)$.

\section{Conclusion}

The study clearly brought out the fact that the treatment protocol employed in the present pilot study is very effective in reducing Viral Load and increasing CD4 count. Also, there was a reduced frequency of opportunistic infections as reported by physicians. These results are quite promising. And as the method is quite simple - just a small fire in a copper pyramid of fixed size and shape at sunrise and sunset which only 
takes say ten minutes in the morning and ten minutes in the evening - this seems to be a method worth examining closer in search for an affordable simple way to control HIV worldwide.

Limitation of the study is that the number of patients was relatively low. Also, there was no control group.

\section{Acknowledgements}

The authors thank all the participants who participated in this study. Our special thanks goes to the organization and all the staff of Ananta Bharatha Charitable Trust ${ }^{\circledR}$ which cares for members of the society who are often stigmatized or just ignored, and to the founder of Ananta Bharatha Charitable Trust ${ }^{\circledR}$.

\section{Further studies}

As this pilot study showed positive results, it has been decided to do a controlled study as next step, having two groups of 20 children with equivalent health conditions, having the same arrangements for accommodation, food and daily routine (like daily Yoga), the only difference being that one group performs Agnihotra daily and the other group does some other activity like Tai Chi or so. Data (both objective and subjective parameters like psychological and social parameters) will be collected and compared after three months, six months and one year. In case the results of this controlled study are as positive as the pilot study suggests, Agnihotra could be further examined and applied as one means to control HIV infection and help the affected people to go back to a life which is worth living. Also, it is suggested to test the effects of Agnihotra Ash on HIV viruses in cell lines.

\section{Authorship contributions}

RD: Initiated and planned for the project.

LD: Provided the statistics.

KP: Monitored the health of all children.
MK: Implemented and coordinated the project and wrote the text.

UB: Supervised the correct performance of Agnihotra and wrote and edited the text.

\section{Source of funding}

Funding for the project was provided by Ananta Bharatha Charitable Trust ${ }^{\circledR}$, Mysore, Karnataka, India.

\section{Conflict of interest}

The authors do not have any conflict of interest.

Received Date: 03-06-20; Revised Date: 15-12-20

Accepted Date: $21-12-20$

\section{References}

1. Carr A, Cooper DA. Adverse effects of antiretroviral therapy. The Lancet. 2000 Oct 21;356(9239):1423-30.

2. Vasant V. Paranjpe, Homa Therapy - Our Last Chance, Madison VA, USA, 1989.

3. Online timings program [Internet]. Homatherapie. [cited 2020 Nov 27]. Available from: http://www.homatherapie.de/en/agnihotra.html

4. Berk Ulrich, Impact of Homa Organic Farming in Mitigating Soil, Water, and other Environmental Crises. IJPE [Internet]. 2020;6(01):56-7.

5. Ulrich Berk, Bruce Johnson (Ed.), Brainstorming Conference - Bringing Homa Organic Farming in to the Mainstream of Indian Agriculture System, Dhule, Maharashtra, India, 2009.

6. Agnihotra Ash Medicines [Internet]. Homa Health. 2020 [cited $2020 \mathrm{Nov}$ 27]. Available from: http://www.homahealth.com/

7. Homa Health Testimonies. Available from: http://homahealth.com/ category/testimonies/

8. G.R. Pathade, Pranay Abhang, Scientific study of Vedic Knowledge Agnihotra, Bharatiya Bouddhik Sampada, 43rd-44th Issue, February/June 2014.

9. Kumar S, Modgil S, Bammidi S, Minhas G, Shri R, Kaushik S, et al. Allium cepa exerts neuroprotective effect on retinal ganglion cells of pterygopalatine artery (PPA) ligated mice. Journal of Ayurveda and Integrative Medicine. 2020.

10. Mathur D, Goyal K, Koul V, Anand A. The molecular links of re-emerging therapy: a review of evidence of Brahmi (Bacopa monniera). Frontiers in pharmacology. 2016;7:44. 